\title{
COMPARISON OF MECHANICAL AND THERMAL COMFORT PROPERTIES OF TENCEL BLENDED WITH REGENERATED FIBERS AND COTTON WOVEN FABRICS
}

\author{
Abdul Basit ${ }^{1}$, Wasif Latif ${ }^{1}$, Munir Ashraf ${ }^{2}$, Abdur Rehman $^{2}$, Kashif Iqbal2 ${ }^{2 *}$, \\ Hafiz Shahzad Maqsood ${ }^{1}$, Abdul Jabbar ${ }^{1}$, Sajjad Ahmad Baig ${ }^{3}$ \\ ${ }^{1}$ Department of Yarn Manufacturing, National Textile University, 37610, Faisalabad, Pakistan \\ ${ }^{2}$ Department of Textile Processing, National Textile University, 37610, Faisalabad, Pakistan \\ ${ }^{3}$ Department of Business Administration, National Textile University, 37610, Faisalabad, Pakistan \\ ${ }^{*}$ Corresponding e-mail address: kashif.tch@gmail.com
}

\begin{abstract}
:
The demand of cotton is increasing but its low production rate cannot fulfill the world requirements. The increase in cotton demand has augmented the production of regenerated cellulosic fibers. Furthermore, cotton has proved to be unsustainable because of the use of huge amount of fresh water, pesticides and insecticides. The purpose of this work is to find out the suitable blend/blends of regenerated fibers so as to replace $100 \%$ cotton fabrics. Therefore, mechanical and comfort properties of Tencel fabrics blended with other regenerated cellulose fibers have been compared with $100 \%$ cotton to achieve the equivalent or even better end properties. Hence, cotton, viscose, Tencel, modal, and bamboo fibers were taken. Plain woven blended fabrics of 100\% cotton and 50:50 blends of Tencel with other regenerated fibers were prepared from normal yarn count of 20 tex. The mechanical properties (warpwise and weft-wise tensile and tear strengths, pilling, and abrasion resistance) and the comfort properties including air permeability, moisture management properties, and thermal resistance were evaluated. It is found that Tencel blended fabrics show better results than $100 \%$ cotton fabrics. Therefore, it is concluded that Tencel blended with these regenerated fabrics can be used to replace $100 \%$ cotton fabrics.
\end{abstract}

\section{Keywords:}

Tencel, regenerated blends, mechanical properties, comfort properties, woven fabrics

\section{Introduction}

The production of textile fibers has grown to nearly 100 million metric tonnes, with major categories being synthetics $(63 \%)$, cotton $(24 \%)$, regenerated cellulosic $(7 \%)$, other natural fibers $(5 \%)$, and wool fibers (1\%) [1]. Of the water present on earth, fresh water that is consumable for human, animal, or plant is $0.65 \%$, and only $0.3 \%$ of fresh water is renewable. Among the different crops, cotton requires much water, damaging freshwater ecosystem globally. Even though cotton fiber is sustainable, the production of $1 \mathrm{~kg}$ of cotton fiber needs more than 20,000 I of water, consuming $24 \%$ and $11 \%$ of global insecticide and pesticides consumption, respectively. Also, cotton crop uses $2.4 \%$ of world's crop land. Moreover, cotton cultivation destructs ecosystems in various parts of the globe [2].

As only $7 \%$ of the regenerated fibers are being used currently, these have great potential for use in textile clothing. Three generations of regenerated cellulosic fibers, such as viscose, modal, bamboo, and Tencel fibers are the most important fibers because of certain properties regarding textiles and environment. Different production processes and conditions for conventional viscose, modal, bamboo, and new Tencel fibers cause differences in the structure of the fibers, although they have similar chemical compositions [3].

The microstructure and thermal properties of Tencel, modal, and viscose fibers were analyzed using DSC, FTIR, and TG. The spectral analysis of FTIR shows that Tencel is highly crystalline than other fibers having crystalline cellulose II and amorphous cellulose. In this way, Tencel is found to have more thermal stability than modal and viscose [4]. All the regenerated fibers are biodegradable, of which Tencel fiber has high strength, which contains water in its structure as a source of heat capacity that helps in human body's temperature regulation.

Modal is a modified form of viscose with induced high wet strength, high comfort, fine lustre, hand, smoothness, wicking properties, and performance properties such as strength and modulus. Bamboo fiber is extremely soft, cool, and breathable and has higher luster and more moisture absorption. In addition, it has anti-UV properties and inherent antibacterial properties. The microgaps and microholes present in the cross section of bamboo fiber enhance moisture absorption and ventilation [5]. Organic Crop Improvement Association (OCIA) has certified bamboo viscose fiber as an organic fiber that can be degraded by microorganisms and sunshine [6]. Viscose fibers are also hydrophilic. These inherent physiological fiber properties are ideal for moisture management. The moisture management properties ensure an ample temperature balance on the skin by enhancing the overall thermal comfort.

Many studies in which Tencel having outstanding properties was blended with other fibers to study different yarn and fabric properties were conducted. Blended yarns of Tencel, cotton, and modal were studied, and it was found that Tencel:cotton blend 
has better mechanical properties [7]. Similarly, it was found that pure Tencel yarns and its blends have better quality than other blends [8]. Tencel gives excellent properties in both pure as well as blended form and can be used in sports wear [9]. In a study of thermal comfort properties of bamboo and Tencel knitted fabrics, it was found that increase in blend ratio of Tencel increases air permeability, water vapor permeability, and increases thermal resistance [10]. Comparative analysis of thermal insulation properties of fabrics made of cotton and Tencel was conducted. The finished Tencel fabrics showed lower values of thermal conductivity and thermal absorption than cotton fabrics and higher values of thermal diffusion and resistance. [11]. Dimensional properties of viscose, modal, and lyocell single jersey knitted fabrics were studied with three different loop lengths in dry, wet and relaxed conditions. The lyocell fabrics showed higher bursting strength and lower spirality than modal and viscose fabrics due to the structure of lyocell fibers [12].

The current research has been focused on the use of Tencel fibers along with other cellulosic blends $(50: 50)$ to replace $100 \%$ cotton fabric because Tencel has better mechanical and comfort properties because of the presence of water in its crystalline structure. The use of regenerated blends to optimize their properties has not been reported yet. The mechanical, thermal, and comfort properties have been evaluated and reported in this study.

\section{Materials and Methods}

\subsection{Materials}

Cotton as well as the regenerated fibers (bamboo, viscose, modal and Tencel) were used in this work. The specifications of all fibers used in this research are elaborated in Table 1.

\section{$\underline{2.2 \text { Methods }}$}

\subsubsection{Yarn Production}

Four blended yarns of 20 tex with different ratios given in Table 2 were prepared. The yarns were produced through ring spinning by blending the fibers in Blow room. The machines used in this study are listed in Table 3.

Table 2. Blend ratios

\begin{tabular}{|c|c|}
\hline Yarns & Ratio \\
\hline Cotton & 100 \\
\hline Tencel:modal & $50: 50$ \\
\hline Tencel:viscose & $50: 50$ \\
\hline Tencel:bamboo & $50: 50$ \\
\hline
\end{tabular}

Table 3. Machinery for Yarn manufacturing

\begin{tabular}{|c|c|c|}
\hline S. No. & Machine & Make \\
\hline 01 & Blow room & Rieter, Truzschler \\
\hline 02 & Card & MK-5 Crosrol \\
\hline 03 & Drawing frame & DX8, RSB D 30 \\
\hline 04 & Comber & Toyoda VC-5A \\
\hline 05 & Simplex & Toyota FL-16 \\
\hline 06 & Ring frame & Toyota RY-4 \\
\hline
\end{tabular}

\subsubsection{Fabric samples preparation}

Plain woven fabrics of $120 \mathrm{gsm}$ having construction of $76 \times 68$ per inch were prepared on CCI loom (model SL 8900S) made of Taiwan. The loom had a reed of 35 with a speed of 36 picks/ min. The total number of warp ends was 1120 .

\subsubsection{Fabric Processing}

The sample fabrics were first desized (detail is given in Table 4 ) and then scoured and bleached (detail is given in Table 5).

Table 4. Detail of Desizing process

\begin{tabular}{|c|}
\hline Detergent $(2 \mathrm{~g} / \mathrm{L})$ \\
\hline Desizer $(5 \mathrm{~g} / \mathrm{L})$ \\
\hline Time $(6 \mathrm{~h})$ \\
\hline Temperature $\left(40^{\circ} \mathrm{C}\right)$ \\
\hline
\end{tabular}

Table 1. Specifications of cotton, Tencel, modal, viscose, and bamboo fibers

\begin{tabular}{|c|c|c|c|c|c|}
\hline Parameters & Cotton & Tencel & Modal & Viscose & Bamboo \\
\hline Breaking Tenacity (cN/tex) & 27.9 & 21 & 25 & 35 & 36 \\
\hline Elongation (\%) & 6.6 & 17 & 20 & 13 & 14 \\
\hline Staple/Cut Length (mm) & 27.3 & 38 & 39 & 39 & 38 \\
\hline Linear Density (dtex) & 1.46 & 1.3 & 1.3 & 1.3 & 1.3 \\
\hline Moisture (\%) & 8.5 & 11 & 11 & 11 & 13 \\
\hline Length Uniformity (\%) & 83.6 & - & - & - & - \\
\hline Micronaire ( $\mu \mathrm{g} / \mathrm{inch})$ & 4.6 & - & - & - & - \\
\hline Rd value & 73.3 & - & - & - & - \\
\hline Short Fiber Index & 33.4 & - & - & - & - \\
\hline$+\mathrm{b}$ value & 8.6 & - & - & - & - \\
\hline
\end{tabular}


Table 5. Detail of Scouring and Bleaching processes

\begin{tabular}{|c|}
\hline $\mathrm{H} 2 \mathrm{O} 2(35 \mathrm{ml} / \mathrm{L}))$ \\
\hline $\mathrm{NaOH}(10 \mathrm{ml} / \mathrm{L})$ \\
\hline Stabilizer $(5 \mathrm{ml} / \mathrm{L}$ \\
\hline Wetting Agent $2(\mathrm{~g} / \mathrm{L})$ \\
\hline Time $(40 \mathrm{~min})$ \\
\hline Temperature $(90 \circ \mathrm{C})$ \\
\hline
\end{tabular}

\subsubsection{Testing}

The mechanical and thermal comfort has been tested as given in Table 6.

\section{Results and Discussion}

\subsection{Properties of Yarns}

The different properties of the prepared yarns are elaborated in Table 7. Moreover, the tenacities and elongation percentage of yarns are represented in Figure 1. The Tencel:modal yarn gives higher strength $(21.42 \mathrm{cN} /$ tex $)$ than other regenerated blends and $100 \%$ cotton fiber. It is due to the higher tenacity of Tencel and modal fibers than bamboo, viscose, and cotton fibers. The Tencel:modal yarn exhibits higher strength as the longer chains of Tencel and modal polymer structure make them highly crystalline, giving high strength [4] [13-14] [1516]. The yarn blends of Tencel with viscose and bamboo and $100 \%$ cotton give the same strength (18.68-19.16 cN/tex). The elongations of all the regenerated blends are found to be same (15.5-15.89\%); however, cotton yarn elongation is only $4.1 \%$ because cotton is a rigid fiber with only $6 \%$ elongation.

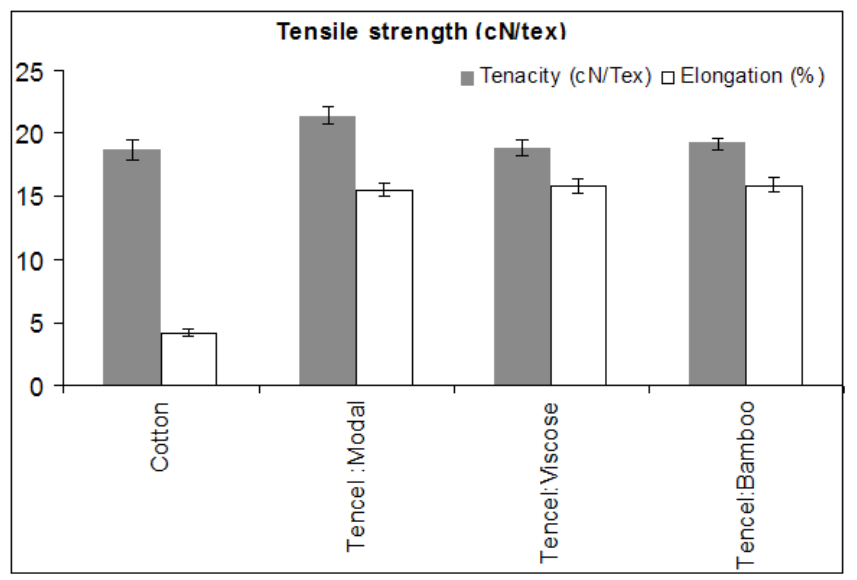

Figure 1. Mechanical properties of yarns

Table 6. Summary of testing

\begin{tabular}{|c|c|c|c|c|}
\hline S. No. & Equipment & Testing & Model & Standard \\
\hline 1 & Yarn tensile tester & Yarn tensile properties & Tensojet 2000 & $\begin{array}{c}\text { ASTM D2256 / D2256M } \\
-10 \mathrm{e} 1\end{array}$ \\
\hline 2 & Tensile tester & $\begin{array}{l}\text { Warp and weft tensile } \\
\text { strength of fabrics }\end{array}$ & 1992 & ASTM D5035 - 11 \\
\hline 3 & Elmendorf's Tear tester & $\begin{array}{l}\text { Warp and weft tear } \\
\text { strength of fabrics }\end{array}$ & 1992 & ASTM D1424 - 09(2013). \\
\hline 4 & Martindale tester & $\begin{array}{l}\text { Determination of pilling } \\
\text { resistance of fabrics }\end{array}$ & 1992 & ASTM D 4970-02 \\
\hline 5 & Martindale abrasion tester & $\begin{array}{l}\text { Determination of abrasion } \\
\text { resistance of fabrics }\end{array}$ & 1992 & ASTM D 4966-98 \\
\hline 6 & $\begin{array}{l}\text { Moisture management } \\
\text { tester }\end{array}$ & $\begin{array}{l}\text { Determination of moisture } \\
\text { management of fabrics }\end{array}$ & M-290 & AATCC 195-2009 \\
\hline 7 & Air permeability tester & Air permeability of fabrics & $M-021 A$ & ASTM D737-04 (2012) \\
\hline 8 & Thermal resistivity tester & $\begin{array}{l}\text { Thermal resistance of } \\
\text { fabrics }\end{array}$ & $M-259 B$ & ASTM D1518-11a \\
\hline
\end{tabular}

Table 7. Properties of yarns

\begin{tabular}{|c|c|c|c|c|c|c|c|c|c|}
\hline Yarn & $\mathrm{Nec}$ & CLSP & $\begin{array}{c}\text { CVm } \\
(\%)\end{array}$ & $\begin{array}{c}\text { Thin } \\
(-50 \%) \\
\left(\mathrm{km}^{-1}\right)\end{array}$ & $\begin{array}{c}\text { Thick } \\
(+50 \%) \\
\left(\mathrm{km}^{-1}\right)\end{array}$ & $\begin{array}{c}\text { Neps } \\
(+200 \%) \\
\left(\mathrm{km}^{-1}\right)\end{array}$ & IPI & $\mathbf{H}$ & $\begin{array}{c}\text { b-f } \\
(\mathrm{cN} / \mathrm{tex})\end{array}$ \\
\hline Cotton & 30.3 & 2404 & 13.45 & 2.5 & 44.2 & 90.8 & 137 & 4.9 & 377 \\
\hline Tencel:modal & 30.4 & 3257 & 12.92 & 0.0 & 22.5 & 26.8 & 49.3 & 6.3 & 430 \\
\hline Tencel:viscose & 30.4 & 2676 & 13.23 & 0.8 & 27.5 & 29.2 & 57.5 & 6.3 & 379 \\
\hline Tencel:bamboo & 30.6 & 2577 & 13.34 & 0.8 & 27.5 & 40 & 68.3 & 5.2 & 365 \\
\hline
\end{tabular}




\subsection{Mechanical Properties of Fabrics}

The graphical representation of tensile and tear strength of the woven fabrics is given in Figure 2. Tencel:modal fabric in warp wise and weft wise gives the higher tensile strength (24 kgf) than other fabrics. It is due to higher strength of Tencel:modal yarn because tensile strength mainly depends on the strength of yarn and fibers. Considering the warp-wise direction, the tensile strength of Tencel:viscose and Tencel:bamboo fabrics was 24 and $21 \mathrm{kgf}$, respectively, however; cotton fabrics has a strength of $24 \mathrm{kgf}$, which is similar to that of Tencel:viscose because their yarns have same strength. Similar is the case in the weft-wise direction as can be seen in Figure $2 a$.

Tear strength depends on the yarn strength and yarn mobility in the fabric structure. The yarn mobility further depends on the yarn twist and fiber and yarn smoothness. Fabric weave being same has no effect in this work. The maximum tear strength (Figure $2 b$ ) in both warp and weft directions is given by Tencel:modal fabric because of the higher strength of Tencel:modal yarns. Cotton yarns were given more twist than the yarns other than cotton as these have lesser fiber length $(27 \mathrm{~mm})$. So cotton fabric has minimum tear strength in both warp and weft directions as the yarn is less strong, more rigid, and less smooth because of more twist and more irregularities (number of imperfections, IPI = 137). Tencel:viscose has more tear strength (although yarns have same strength and twist) than Tencel:bamboo because Tencel:viscose yarn (IPI= 28.2) is smoother than Tencel:bamboo yarn (IPI $=41.4)$ so yarns may have better mobility in Tencel:viscose fabrics.

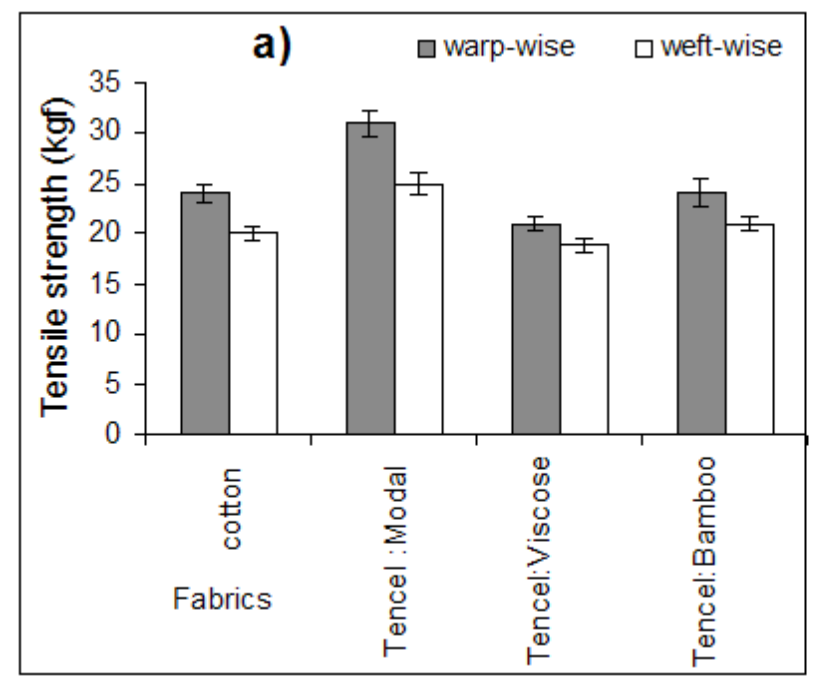

Pilling is a fabric surface defect due to fiber movement or slippage of yarns caused by abrasion and wear. Pilling occurs in four steps: fuzz formation, entanglement, growth, and wear off. The formation of fuzz and pills influence the fabric surface, which affects the esthetics and durability of a fabric and its acceptance by consumers. Similarly, abrasion is the rubbing of a textile surface over another surface, which damages the fibers, yarns, and fabrics. The results of propensity to pilling of fabrics and their abrasion resistance are given in Table 8. Cotton shows more pilling and lower abrasion resistance; however, Tencel:modal, Tencel:viscose, and Tencel:bamboo have lower pilling and higher abrasion resistance than other blends. Pilling and abrasion resistance depends on numerous factors such as fiber type, inherent mechanical properties of the fibers, fiber dimensions, yarn structure, and construction and thickness of the fabrics. Cotton gives more pilling and lower abrasion resistance because cotton fibers have lower extension at break and work of rupture and lower ability to withstand repeated distortion and, hence, offer less resistance to pilling and abrasion.

\subsection{Comfort Properties}

\subsubsection{Air Permeability}

For a woven fabric, nature of fiber, yarn twist, yarn linear density, and yarn structure affect the air permeability. As yarn twist is increased, the yarn diameter and the cover factor are decreased, resulting in increase in the air permeability. Increase in yarn twist may also make more circular yarn, making the

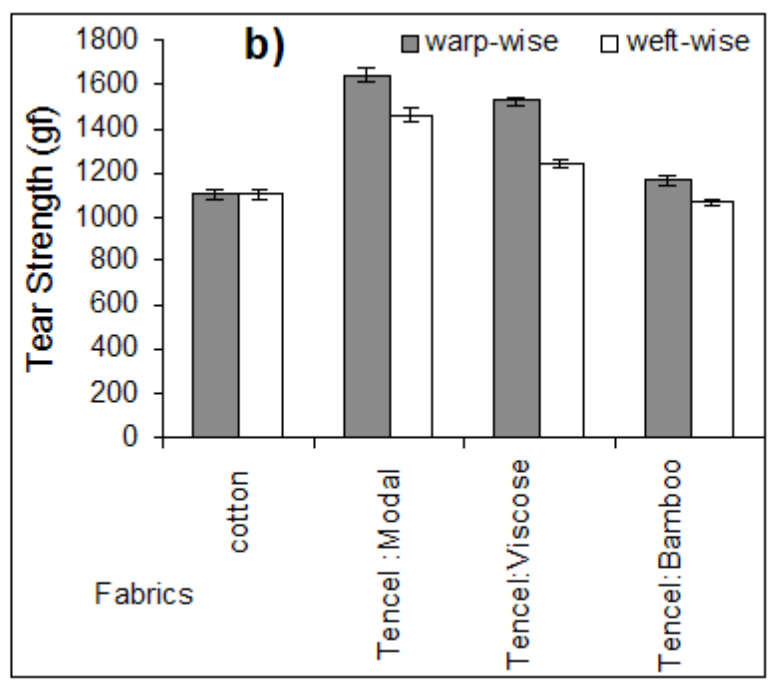

Figure 2. (a) Tensile strength and (b) tear strength of woven fabrics

Table 8. Mechanical properties of fabrics, pilling scale 1 to $5(1=$ dense surface fuzzing and/or severe pilling and $5=$ no change $)$.

\begin{tabular}{|c|c|c|c|c|c|c|}
\hline \multirow{2}{*}{ Material } & \multicolumn{2}{|c|}{ Tensile strength (kgf) } & \multicolumn{2}{c|}{ Tear strength (gf) } & Pilling resistance \\
\cline { 2 - 6 } & Warp & Weft & Warp & Weft & $\begin{array}{c}\text { Abrasion resistance } \\
\text { (After 1,000 cycle) }\end{array}$ & (yarns break at cycles) \\
\hline Cotton & 24 & 20 & 1,100 & 1,100 & 2 & 12,000 \\
\hline Tencel:modal & 31 & 25 & 1,440 & 1,460 & 3.5 & 21,500 \\
\hline Tencel:viscose & 21 & 24 & 1,520 & 1,240 & 3 & 16,750 \\
\hline Tencel:bamboo & 24 & 25 & 1,160 & 1,065 & 3 & 16,000 \\
\hline
\end{tabular}


fabric more air permeable. Fabrics having higher-density yarns are closely packed in a tight woven structure, with reduction in air permeability [17-18]. Fiber cross section affects on the intra-yarn spaces, which further affects the fabric porosity [19]. Tencel:modal fabric (Figure 3a) gives maximum air permeability $(605 \mathrm{~mm} / \mathrm{s})$. Modal and Tencel fibers have such fiber structure containing channels that increase the porosity of fabric. Tencel:viscose and Tencel:bamboo have an air permeability of 530 and $516 \mathrm{~mm} / \mathrm{s}$, respectively, and, hence, are more air permeable than cotton $(391 \mathrm{~mm} / \mathrm{s})$. Tencel:Viscose is more air permeable than Tencel:bamboo, which might be due to more regularity of Tencel:viscose yarn (IPI = 28.2). Cotton fabric is least air permeable as cotton fiber is coarser (1.46 dtex) than other fibers (1.3 dtex), so cotton fabric has less intra-yarn spaces. Moreover, cotton yarns have more imperfections (IPI = 137), which may cause more air resistance giving less air permeability.

\subsubsection{Moisture Management}

Moisture management is a one-way transport of moisture and overall moisture management capacity (OMMC) of a fabric [5]. The results for OMMC are given in Figure $3 \mathrm{~b}$. The Tencel:modal, Tencel:viscose, and Tencel:bamboo fabrics give better moisture management than cotton fabrics. Cotton, bamboo, and viscose fibers are hygroscopic but the moisture regain of cotton fiber is $8.5 \%$ compared to $11 \%$ for bamboo and viscose fibers; thus they readily absorb water. Hence, bamboo and viscose fibers absorb more than they spread, resulting relatively in lower OMMC as compared to cotton fiber. It is generally known that cotton has moisture absorption ability. Lumen appears in the center when fiber matures. Lumen helps in water absorption by drawing water through capillary action (wicking) which makes it a comfortable fiber [20]. Considering Figure 4b, Tencel:viscose and Tencel:bamboo give better moisture management than cotton, which is due to the Tencel fibers that absorbs and spreads moisture readily.lt has nano-channels (present in core) through which water is transported making it efficient in moisture management. Tencel has a unique fibril structure, tiny components that make up the fiber. Submicroscopic channels between the individual fibrils regulate the absorption and release of moisture. Tencel completely absorbs and then releases the moisture outside, giving the wearer a comfortable feel [21].

\subsubsection{Thermal resistance}

Figure $3 c$ presents the thermal resistance of the woven fabrics. In this work, as yarn and fabric parameters are same, the thermal resistance mainly depends on the nature of the fibers. Tencel:modal provides more heat resistance than Tencel:bamboo, Tencel:viscose, and cotton. As bamboo and viscose are thermally conductive than cotton [22-23], Tencel proves to be more thermal resistant. The nanostructure of Tencel fibers is different from the other known cellulose fibers. Nanostructure of Tencel consists of the nanofibrils and nanochannels that manage the moisture of the body produced in case of perspiration or sweating [24]. This property of Tencel has made it thermally resistive. Cotton fabrics show the least thermal resistance. It is due to their intrinsic convolutions present in cotton fiber, which offers thermal resistance by entrapping air in the convolutions. This air captures the body heat which is slowly released. But the thermal resistance of cotton is less when compared to Tencel and modal. Although
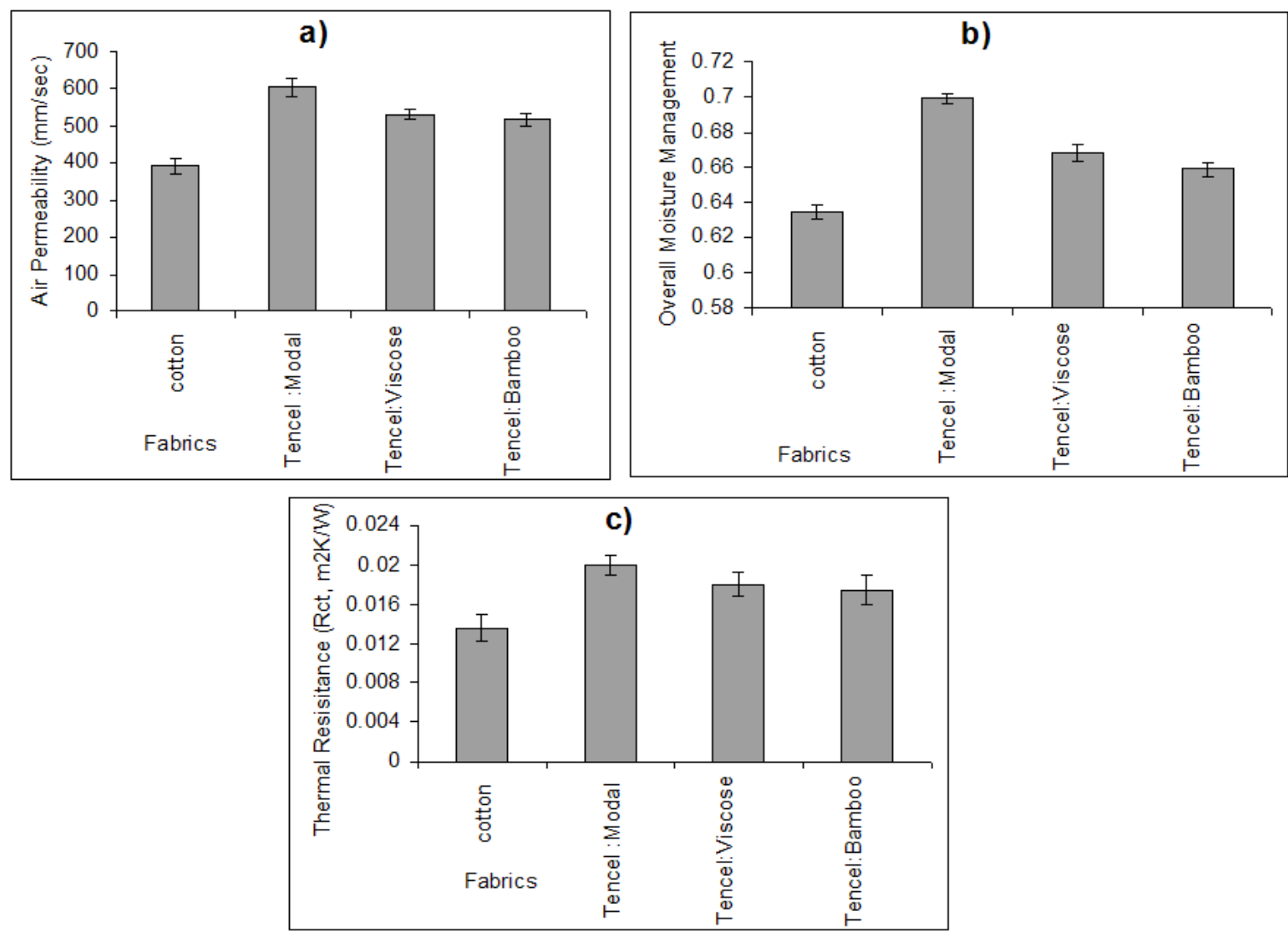

Figure 3 (a) Air Permeability, (b) Moisture Management, (c) Thermal Resistance of fabrics 
Tencel:modal, Tencel:bamboo, and Tencel:viscose appear to be more thermal resistant than cotton and their air permeability and moisture management properties are much better than cotton, Tencel:modal, Tencel:bamboo, and Tencel:viscose have more overall more comfort than $100 \%$ cotton fabrics.

\section{Conclusion}

In this work, Tencel was blended with modal, viscose, and bamboo against $100 \%$ cotton fabric. The mechanical and comfort properties were studied and compared. It is found that Tencel:modal blended fabric showed higher mechanical (tensile and tear strength, pilling, and abrasion resistance) and comfort properties (moisture management, thermal resistance, and air permeability) of all blends under investigation. In addition, Tencel:viscose and Tencel:bamboo gave better mechanical and comfort properties than $100 \%$ cotton. Hence, it can be concluded that Tencel blended with modal, viscose, and bamboo fabrics are better than less-sustainable pure cotton fabrics. So, the clothings that are being made by pure cotton fabrics can be replaced by Tencel blended with other regenerated fabrics that give improved properties (mechanical and comfort properties).

\section{References}

[1] Lenzing.The Global Fiber Market in 2016 http://www. lenzing.com/en/investors/equity-story/global-fiber-market. html

[2] Bellon-Maurel, V., Peters, G.M., Clermidy, S., Frizarin, G., Sinfort, C., et al. (2015). Streamlining life cycle inventory data generation in agriculture using traceability data and information and communication technologies-part II: application to viticulture, Journal of cleaner production, 87(119-129.

[3] Kayseri, G.O., Bozdogan, F. and Hes, L. (2010). Performance properties of regenerated cellulose fibers, Tekstil ve Konfeksiyon, 20(3). 208-212.

[4] Carrillo, F., Colom, X., Sunol, J. and Saurina, J. (2004). Structural FTIR analysis and thermal characterisation of lyocell and viscose-type fibres, European Polymer Journal, 40(9). 2229-2234.

[5] Prakash, C., Ramakrishnan, G. and Koushik, C.V. (2013). A study of the thermal properties of bamboo knitted fabrics, Journal of Thermal Analysis and Calorimetry, 111(1). 101-105.

[6] Rana, S., Pichandi, S., Parveen, S. and Fangueiro, R., "Regenerated cellulosic fibers and their implications on sustainability," in Roadmap to Sustainable Textiles and Clothing, ed: Springer, 2014, pp. 239-276.

[7] Kilic, M. and Okur, A. (2011). The properties of cottonTencel and cotton-Promodal blended yarns spun in different spinning systems, Textile Research Journal, 81(2). 156-172.

[8] Xijun, W.H.Y. (2007). Development of Tencel Fiber Pure Yarn and Tencel Blended yarn [J], Cotton Textile Technology, 10 (p020.
[9] Firgo, H., Suchomel, F. and Burrow, T. (2006). Tence/® high performance sportswear, Lenzinger Berichte, 85(4450.

[10] Shanmugasundaram, G.K.G.N.O. (2016). Thermal comfort properties of bamboo tencel knitted fabrics, Science and Technology, 28(4). 420-428.

[11] Frydrych, I., Dziworska, G. and Bilska, J. (2002). Comparative analysis of the thermal insulation properties of fabrics made of natural and man-made cellulose fibres, Fibres and Textiles in Eastern Europe, 10(4). 40-44.

[12] Sakthivel, J.C. and Anbumani, N. (2012). Dimensional Properties of Single Jersey Knitted Fabrics Made with New and Regenerated Cellulosic Fibers, Journal of Textile and Apparel, Technology and Management, 7(3).

[13] Kreze, T. and Malej, S. (2003). Structural characteristics of new and conventional regenerated cellulosic fibers, Textile Research Journal, 73(8). 675-684.

[14] Stana-Kleinschek, K., Ribitsch, V., Kreže, T., SfiligojSmole, M. and Peršin, Z. (2003). Correlation of regenerated cellulose fibres morphology and surface free energy components, Lenzinger Berichte, 82(1). 83-95.

[15] Uchida, Y. (1967). Problems of Polynosic and high wet modulus-fibres, Pure and Applied Chemistry, 14(3-4). 461474.

[16] Erdumlu, N. and Ozipek, B. (2008). Investigation of regenerated bamboo fibre and yarn characteristics, Fibres \& Textiles in Eastern Europe, 16(4), p 69.

[17] Permeability, A. Standard Test Method for Air Permeability of Textile Fabrics, ASTM D737-96.

[18] Kullman, R.M., Graham JR, C.O. and Ruppenicker, G.F. (1981). Air permeability of Fabrics made from unique and Conventional yarns, Textile Research Journal, 51(12). 781-786.

[19] Tascan, M. and Vaughn, E.A. (2008). Effects of fiber denier, fiber cross-sectional shape and fabric density on acoustical behavior of vertically lapped nonwoven fabrics, Journal of Engineered Fibers and Fabrics, 3(2). 32-38.

[20] Gun, A.D. (2011). Dimensional, physical and thermal properties of plain knitted fabrics made from 50/50 blend of modal viscose fiber in microfiber form with cotton fiber, Fibers and Polymers, 12(8). 1083-1090.

[21] Leading fibre innovation (25 April)Available: www.Lenzing. com

[22] Tyagi, G., Krishna, G., Bhattacharya, S. and Kumar, P. (2009). Comfort aspects of finished polyester-cotton and polyester-viscose ring and MJS yarn fabrics.

[23] Abu-Rous, M., Ingolic, E. and Schuster, K. (2006). Visualisation of the Nano-Structure of Tence/®(Lyocell) and Other Cellulosics as an Approach to Explaining Functional and Wellness Properties in Textiles, Lenzinger Berichte, 85(31-37.

[24] Männer, J., Schuster, K.C., Suchomel, F., Gürtler, A. and Firgo, $H$. (2004). Higher performance with natural intelligence, Lenzinger Berichte, 83(99-110. 